JURNAL INKLUSIF : Jurnal Pengkajian Penelitian Ekonomi dan Hukum Islam Vol: 4 No: 1 June 2019 Published by Pascasarjana IAIN Syekh Nurjati Cirebon, Indonesia. p-ISSN: 2303-2669, e-ISSN: 2548-9631

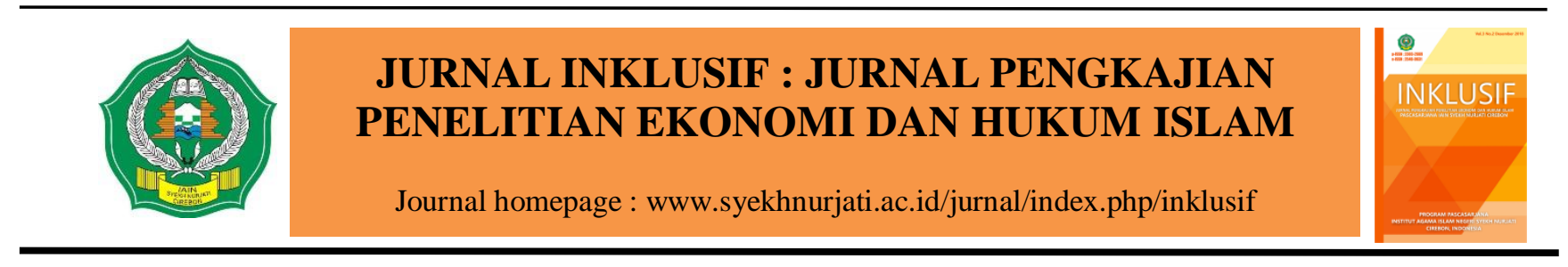

\title{
ANALISIS PEMBERDAYAAN EKONOMI MASYARAKAT MELALUI PENYALURAN ZAKAT PRODUKTIF DI LAZ ZAKAT CENTER CIREBON
}

Abdul Aziz ${ }^{1}$

Euis Prihastini Zakiah

Email : abdulazizmunawar11@gmail.com

prihastinizakiah95@gmail.com

\section{Artikel info:}

Received: 21

December 2018

Revised form: 3

January 2019

Accepted: 7

February 2018

Available online:

17 Mei 2019
Zakat is an instrument of Islamic teachings that are concerned with humanitarian issues, especially relating to the topic of empowerment and economic welfare of the people. In the early days, zakat was given to Mustahik to deal with problems of financial difficulties consumptively and productively. However, today, the distribution of zakat is considered still not providing the first solution to poverty alleviation. What is done by several zakat institutions, including the Amil Zakat (LAZ) Alms Center of Thoriqotul Jannah in collecting and distributing zakat funds is part of an effort to fill the space. Providing productive business capital for Mustahik to be able to develop business is one of the efforts carried out by the LAZ. It is expected that the Mustahik who initially accept can someday give to become Muzakki.

Keywords: Empowerment, Economy, Society, Distribution, Zakat

\section{ABSTRAK}

Zakat adalah instrumen ajaran Islam yang berkaitan dengan masalah kemanusiaan, terutama tentang masalah pemberdayaan dan kesejahteraan ekonomi rakyat. Pada masamasa awal, zakat diberikan kepada Mustahik untuk menghadapi masalah kesulitan keuangan secara konsumtif dan produktif. Namun, saat ini, distribusi zakat dianggap masih belum memberikan solusi mendasar untuk pengentasan kemiskinan. Apa yang dilakukan oleh beberapa lembaga zakat, termasuk Pusat Sedekah Amil Zakat (LAZ) Thoriqotul Jannah dalam mengumpulkan dan mendistribusikan dana zakat adalah bagian dari upaya mengisi ruang tersebut. Memberikan modal bisnis yang produktif bagi Mustahik untuk dapat mengembangkan bisnis adalah salah satu upaya yang dilakukan oleh LAZ. Diharapkan bahwa Mustahik yang awalnya menerima dapat suatu hari nanti bisa menjadi Muzakki.

Kata kunci: Pemberdayaan, Ekonomi, Masyarakat, Distribusi, Zakat

\footnotetext{
${ }^{1}$ Dosen Pascasarjana IAIN Syekh Nurjati Cirebon.
} 


\section{PENDAHULUAN}

Fenomena kemiskinan sangatlah menarik untuk dikaji, karena kemiskinan merupakan penyakit sosial ekonomi, yang dimana keadaan tersebut akibat dari ketidakmampuan untuk memenuhi kebutuhan dasar seperti makanan, pakaian dan tempat berlindung, pendidikan serta kesehatan. Kemiskinan sebagai ketidakmampuan seseorang dalam memenuhi kebutuhan mereka sendiri. ${ }^{2}$ Menurut BPS (Badan Pusat Statistik), pada bulan Maret 2016 jumlah penduduk miskin di Indonesia mencapai 28,01 juta orang atau sekitar 10,86\%, berkurang sebesar 0,50 juta orang dibandingkan dengan kondisi pada bulan September 2015 yang sebesar 28,51 juta orang sekitar $11,13 \%{ }^{3}$ Meskipun demikian, agar jumlah penduduk miskin terus berkurang dari tahun ke tahun perlu adanya suatu tindakan yang harus dilakukan oleh pemerintah maupun masyarakat.

Dalam Islam cara untuk mengentaskan kemiskinan salah satunya adalah dengan pemungutan zakat dan mendistribusikannya secara adil. Pada zaman Rasulullah pun telah diajarkan untuk peduli dan saling berbagi kepada sesama khususnya bagi orang-orang miskin, dengan membayar zakat. Dari masa Nabi SAW., sampai pertengahan pertama masa pemerintahan Khalifah Utsman, zakat dipungut oleh negara. Zakat dibagikan kepada yang berhak, tidak dengan sistem memberikan sejumlah uang tertentu yang segera habis dimakan, tetapi dengan jalan menjadikan uang zakat sebagai modal usaha yang menyerap tenaga kerja dari mereka yang berhak atas bagian zakat. ${ }^{4}$

Dalam konteks pendistribusian zakat ini dapat diidentikkan dengan konsep pemberdayaan ekonomi. Pemberdayaan merupakan sebuah proses dan tujuan. Sebagai proses, pemberdayaan adalah serangkaian kegiatan untuk memperkuat kekuasaan atau keberdayaan kelompok lemah dalam masyarakat, termasuk individu-individu yang mengalami masalah kemiskinan. Pemberdayaan pada intinya adalah pemanusiaan, yang artinya mengutamakan usaha sendiri dari orang yang diberdayakan untuk meraih keberdayaannya. ${ }^{5}$ Dengan begitu, pemberdayaan masyarakat itu sendiri merupakan upaya untuk memandirikan masyarakat, dengan menggunakan potensi kemampuan yang dimiliki oleh masyarakat itu sendiri. Sebab manusia yang berdaya adalah manusia yang mampu menjalankan harkat martabatnya sebagai manusia, artinya bahwa manusia tidak harus terbelenggu oleh lingkungan, akan tetapi semata-mata menjadikan nilai-nilai luhur kemanusiaan sebagai control terhadap sikap perilakunya. ${ }^{6}$

Pemberdayaan tersebut dapat dilakukan secara efektif melalui lembaga pengelolaan zakat. Namun, banyaknya yang beranggapan bahwa menyalurkan zakat langsung kepada

\footnotetext{
${ }^{2}$ Nurul Huda Et.all, Ekonomi Pembangunan Islam (Jakarta: Prenadamedia Group, 2015).23.

3 BPS, “Kemiskinan," n.d., bps.go.id.

${ }^{4}$ Abdul Aziz, Manajemen Investasi Syariah (Bandung: Alfabeta, 2010).227.

${ }^{5}$ Moh. Ali Aziz Et.All, Dakwah Pemberdayaan Masyarakat: Paradigma Aksi Metodologi (Yogyakarta: Pustaka Pesantren, 2009).169.

${ }^{6}$ Emi Febrina Harahap, "Pemberdayaan Mayarakat Dalam Bidang Ekonomi Untuk Mewujudkan Ekonomi Nasional Yang Tangguh Dan Mandiri," Manajemen Dan Kewirausahaan 3, no. 2 (2014): 23.
} 
mustahiq adalah lebih baik dan lebih afdhal ${ }^{7}$ adalah suatu hal yang kurang tepat, karena kurangnya pengawasan dan pembinaan dengan memberikan zakat secara langsung kepada mustahiq tidak menentukan bahwa mustahiq tersebut dapat berdaya sampai jangka panjang, melainkan hanya pada jangka pendek saja.

Dengan adanya organisasi pengelola zakat dan infak/sedekah dibentuk bertujuan untuk membantu umat muslim di Indonesia sebagai salah satu sarana ibadah. Organisasi pengelola zakat dan infak/ sedekah ini merupakan organisasi yang bergerak dalam bidang penghimpun dan penyaluran dana zakat dan infak/ sedekah yang berasal dari muslim yang membayar zakat (Muzakki) untuk orang membutuhkan yang telah ada dalam aturan dan ajaran agama yang disebut mustahiq atau penerima zakat.

Dengan adanya Lembaga Amil Zakat (LAZ), pemberian zakat tidak begitu saja, melainkan dengan adanya pendampingan, pengarahan serta pembinaan yang akan benarbenar dijadikannya dana zakat tersebut sebagai modal usaha. LAZ yang dapat melakukan penerimaan dan pendistribusian dana zakat, yaitu; LAZ Zakat Center. LAZ Zakat Center ini mempunyai berbagai macam program untuk memberdayakan para mustahiqnya, seperti Ekonomi Mandiri, Pengembangan Wakaf Produktif, dan lain sebagainya. Zakat Center merupakan lembaga pengelola zakat, infak dan shadaqoh yang bersifat nirlaba. Zakat center telah mendapatkan sertifikat system manajemen mutu International Organization for Standardization (ISO) 9001 tahun 2008. Adapun permasalahan dalam penelitian ini adalah bagaimana proses pemberdayaan masyarakat melalui zakat produktif, bagaimana peran Zakat Center dalam upaya pemberdayaan ekonomi Mustahik serta bagaimana mekanisme penyaluran zakat produktif dalam upaya pemberdayaan ekonomi Mustahik.

\section{METODE PENELITIAN}

Metode penelitian ini menggunakan ekploratory dengan pendekatan kualitatif. Analisis deskriptif, dengan sumber data primer yang berasal dari wawancara mendalam ditempuh. Analisa deskriptif digunakan untuk mendeskripsikan suatu gejala, peristiwa, kejadiaan saat sekarang. Pendekatan deskriptif memusatkan perhatian pada masalah aktual sebagaimana adanya pada saat penelitian berlangsung. ${ }^{8}$

Peneliti menggambarkan karakteristik suatu fenomena atau keadaan yang sebenarnya terjadi di lapangan, dan ditujukkan untuk memahami serta mendeskripsikan analisis pemberdayaan ekonomi masyarakat melalui zakat produktif yang didistribusikan oleh LAZIS Zakat Center. Melalui pengumpulan data dengan wawancara (indept-interview) dilakukan guna memperoleh beberapa informasi dari responden ditinjau dari pelaksanaannya mengenai

7 Tim Redaksi Iqtishodia, “Mendudukan Arah Transformasi Lembaga Amil Zakat (LAZ)," Ekonomi Islam Republika 4, no. 2 (2010): 65.

${ }^{8}$ Noor Juliansyah, Metodologi Penelitian: Skripsi, Tesis, Disertasi, Dan Karya Ilmiah (Jakarta: Kencana Prenada Media Group, 2011).34-35. 
pemberdayaan ekonomi masyarakat melalui LAZ zakat center. Adapun informan terdiri dari pengurus dan mustahiq.

\section{PEMBAHASAN}

\section{A. Proses pemberdayaan Masyarakat melalui Zakat Produktif}

Mengenai pemberdayaan, dasar dari strategi pemberdayaan masyarakat dalam pengembangan ekonomi kerakyatan, seperti usaha ekonomi yang lemah merupakan usaha untuk memandirikan masyarakat lewat wirausaha perwujudan potensi dana potensial yang perlu dikelola secara professional dan bertanggung jawab untuk memajukan kesejahteraan umum. Seperti program pemberdayaan yang dilaksanakan oleh Zakat Center dalam pendayagunaan dana zakat dengan target jangka panjang dan dari konsep tersebut dapat mensejahterakan Mustahik, dan besar kemungkinan dikemudian hari jadilah Mustahik sebagai Muzakki. ${ }^{9}$

Menurut bapak Hilman ${ }^{10}$ selaku P2D, Zakat Center mempunyai program pemberdayaan zakat produktif yaitu setiap program yang digulirkan untuk misi-misi produktif, adapun program unggulan untuk misi produktif yaitu E-Man (Ekonomi Mandiri), ada juga program pendidikan atau disebut CERIA (Cerdas Mulia).Terkait dengan penyaluran dan pendayagunaan dana zakat, Zakat Center mempunyai program untuk melaksanakan pemberdayaan para Mustahik mitra binaannya, yaitu program E-Man (Ekonomi Mandiri) dengan kebutuhan ekonomi dan program CERIA untuk pendidikan, dimana kedua program tersebut merupakan program yang mempunyai jangka waktu yang panjang.

Untuk memaksimalkan pemberdayaan masyarakat, terdapat instrument-instrument yang dilakukan oleh Zakat Center dengan aspek:

1. Menciptakakan iklim, memperkuat daya, dan melindungi:

a. Enabling Menciptakan suasana yang memungkinkan untuk meningkatkan potensi yang dimiliki masyarakat, yaitu dengan memberikan dorongan, motivasi kepada para Mustahik, dan melakukan pendampingan.

b. Empowering: Memperkuat potensi yang dimiliki masyarakat, dengan kata lain adanya program-program yang akan membuat Mustahik tersebut menjadi berdaya.

c. Protecting: Melindungi masyarakat dari suatu kemungkinan kembali terjatuhnya ke dalam kemiskinan. Perlindungan yang diberikan dengan melaksanakan ajaran mengenai zakat, infaq, dan shadaqah karena sesungguhnya ajaran tersebut mendorong kaum muslimin untuk terus bekerja keras dan memiliki etos kerja.

2. Menjalankan program pembangunan masyarakat melalui zakat

Tujuan utama dari pembangunan masyarakat yaitu menciptakan kondisi untuk tumbuhnya suatu masyarakat agar berkembang secara berswadaya, dan sasaran dari program pembangunan masyarakat ini adalah peningkatan kualitas taraf hidup masyarakat,

\footnotetext{
${ }^{9}$ Totok dan Poerwoko Soebiato Mardikanto, Pemberdayaan Masyarakat (Bandung: Alfabeta, 2012).2.

${ }^{10}$ Hilman, "Pemberdayaan Masyarakat Melalui Zakat Produktif," (n.d.).
} 
meningkatkan produktivitas, serta kemampuan masyarakat yang tergolong miskin untuk berkembang secara mandiri. ${ }^{11}$ Caranya adalah dengan:

a. Melakukan sosialisasi kepada masyarakat miskin mengenai pengelolaan dana zakat. Untuk menciptakan lapangan pekerjaan serta dapat menjadikan masyarakat miskin memiliki jiwa entrepeneurship, sosialisi yang dilakukan kepada masyarakat miskin, mengenai pendayagunaan dana zakat untuk pemberian modal usaha, memberi pengetahuan mengenai wiraswasta agar modal usaha yang diberikan melalui dana zakat dapat berkembang secara produktif, artinya bahwa modal yang diberikan bisa berputar secara maksimal dan dapat memiliki keuntungan, dan diupayakan agar adanya perubahan status sosial seorang Mustahik dapat menjadi seorang Muzakki.

b. Melakukan Sosialisi dalam bidang pendidikan dilakukan oleh Zakat Center, lembaga amil zakat mengadakan sosialisasi ke sekolah-sekolah mengenai pengadaan beasiswa pendidikan untuk siswa yang tergolong miskin. Amil zakat menggorganisir siswa yang tergolong miskin agar dana zakat dapat disalurkan secara tepat sasaran. Sosialisasi di bidang pendidikan bertujuan agar adanya perbaikan pendidikan, sehingga siswa yang tergolong miskin ini dapat merubah hidupnya lebih layak lagi.

\section{B. Peran Zakat Center dalam Upaya Pemberdayaan Ekonomi Mustahik}

Dalam menjalankan perannya sebagai fasilitator zakat, pihak Zakat Center menjalankan program-program yang hasilkan dan disalurkan untuk kesejahteraan para kaum dhuafa (lemah) yang ada di Zakat Center dan masyarakat umum yang tidak mampu, melalui:

1. Mensosialisasikan dengan memberikan penyuluhan kepada masyarakat mengenai pentingnya ber-zakat serta potensi zakat kepada masyarakat yang mampu membayar zakat (Muzakki).

2. Memberikan bantuan modal usaha untuk Mustahik yang berprofesi sebagai pedagang mikro dengan tujuan supaya usahanya dapat berkembang.

3. Memberikan bantuan sandang pangan kepada Mustahik melalui bantuan dana.

4. Memberikan bantuan pendidikan untuk siwa-siswa yang tidak mampu, dengan sarana prasarana pendidikan pesantren, serta anak yatim yang ditempatkan di Griya Tahfidz yang dikelola oleh Zakat Center, tujuannya supaya anak-anak itu tetap melanjutkan sekolah dengan harapan di masa depan kehidupannya dapat berubah dan dapat menjadi generasi yang mumpuni.

5. Memberikan bantuan kesehatan dengan nama program PROTAKES, program tersebut diberikan kepada masyarakat yang kurang mampu supaya dapat hidup sehat.

Peran yang dilakukan oleh Zakat Center tidak terlepas dari kepercayaan Muzakki sebagai orang yang menyalurkan sebagian hartanya kepada lembaga amil zakat, seperti

${ }^{11}$ Aprillia et.all Theresia, Pembangunan Berbasis Masyarakat (Bandung: Alfabeta, 2014).12. 
yang dikatakan oleh Direktur Zakat Center, yaitu kepercayaan merupakan salah satu yang sangat penting, terutama bagi lembaga zakat. Tanpa adanya kepercayaan dari masyarakat maka habislah lembaga itu, karena dengan itu Zakat Center selalu berupaya dalam membuktikan kepada masyarakat bahwasannya masih ada lembaga zakat yang dapat dipercaya untuk menyalurkan dana zakat, bukan hanya tepat sasaran melainkan bagaimana yang diberi itu dapat berubah kualitas hidupnya.

Zakat Center memiliki cara tersendiri untuk meningkatkan kepercayaan masyarakat, yaitu: Membuat bulletin, Memberikan informasi-informasi mengenai Zakat Center di web dan juga di media sosial, dan Menampilkan Mustahik yang sudah dibantu oleh Zakat Center.

Untuk melihat seberapa besar peran Zakat Center dapat dilihat juga dari hasil pengumpulan dana ZIS, dimana setiap tahunnya pengumpulan hasil dari ZIS meningkat bisa dilihat dalam grafik berikut ini: ${ }^{12}$

\section{HASIL ZIS LAZ ZAKAT CENTER}

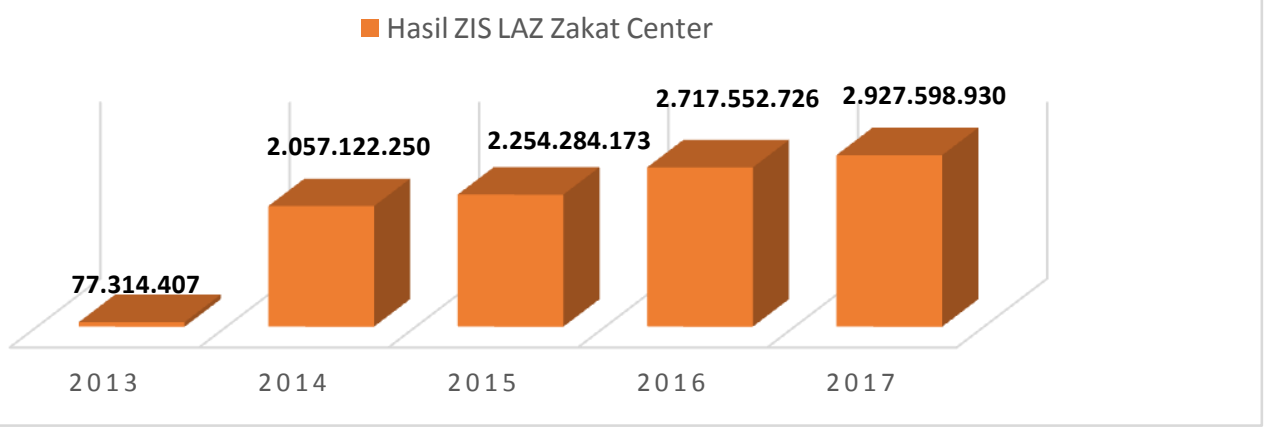

Grafik Hasil ZIS LAZ Zakat Center

Terlihat dari grafik di atas, bahwa semakin berjalannya dan usaha yang dilakukan oleh Zakat Center dalam meningkatkan kepercayaan masyarakat. Zakat Center berhasil membuktikan bahwa lembaga zakat dapat dipercaya. Pemberdayaan yang dilakukan pada dana zakat yang disalurkan oleh Zakat Center itu sebagian besar untuk kategori produktif dan sebagian kecilnya untuk kategori konsumtif. Dimana presentase zakat produktif sekitar $65 \%$ sedangkan untuk zakat konsumtif yaitu $35 \%$ saja. Hal tersebut dapat dilihat dari table dibawah ini: ${ }^{13}$

Tabel Penyaluran Dana Zakat

\begin{tabular}{|c|l|c|c|}
\hline NO & \multicolumn{1}{|c|}{ SUMBER DANA } & JUMLAH & VOL \\
\hline 1 & $\begin{array}{l}\text { PANA ZAKAT } \\
\text { Fakir Miskin }\end{array}$ & Rp 8,625,000 & 3 \\
\hline 2 & Penyaluran Zakat Program " Ekonomi & Rp 94,965,200 & 51 \\
\hline
\end{tabular}

\footnotetext{
12 Zakat Center, "Laporan Keuangan Zakat Center 2013-2017,” n.d.

${ }^{13}$ Zakat Center, "Laporan Penyaluran Dana 2017," n.d.
} 


\begin{tabular}{|c|c|c|c|c|}
\hline & Mandiri " (E-Man) - Fakir Miskin & & & \\
\hline 3 & $\begin{array}{l}\text { Penyaluran Zakat Program " Cerdas Mulia " } \\
\text { (Ceria) - Fakir Miskin }\end{array}$ & $\mathrm{Rp}$ & $132,635,300$ & 80 \\
\hline 4 & $\begin{array}{l}\text { Penyaluran Zakat Program " Sekolah Binaan } \\
\text { " - Fakir Miskin }\end{array}$ & $\mathrm{Rp}$ & $21,808,500$ & 15 \\
\hline 5 & Penyaluran Zakat Program Peduli Muallaf & $\mathrm{Rp}$ & 500,000 & 1 \\
\hline 6 & Penyaluran Zakat Program Peduli Riqob & $\mathrm{Rp}$ & - & 0 \\
\hline 7 & Penyaluran Zakat Program Peduli Ghorimin & $\mathrm{Rp}$ & - & 0 \\
\hline 8 & Penyaluran Zakat Program Peduli Fisabilillah & $\mathrm{Rp}$ & $56,951,900$ & 28 \\
\hline \multirow[t]{2}{*}{9} & Penyaluran Zakat Program Peduli Ibnu Sabil & $\mathrm{Rp}$ & 130,000 & 2 \\
\hline & JUMLAH PENYALURAN & \multicolumn{3}{|c|}{$\operatorname{Rp} 315,615,900$} \\
\hline
\end{tabular}

\section{Mekanisme Penyaluran Zakat Produktif dalam Upaya Pemberdayaan Ekonomi Mustahik}

Dalam menciptakan suasana yang kondusif dan menyelesaikan persoalan-persoalan yang ada, LAZ Zakat Center terus berusaha dalam memberdayakan masyarakat Cirebon. Upaya tersebut meliputi, antara lain bantuan yang bersumber dari ZIS berkategori produktif, dimana kategori produktif tersebut memiliki dua sasaran, yaitu:

Pertama, bantuan dalam bentuk beasiswa pendidikan bagi kaum dhuafa, yang mana bantuan tersebut diberikan kepada anak-anak yang akan melanjutkan ke jenjang SMP/MTs, dengan masa pendidikan selama 3 tahun. Serta bantuan beasiswa yang diberikan untuk melanjutkan ke perguruan tinggi. Pada tahun 2017 LAZ Zakat Center telah mengalokasikan dana beasiswa kepada 47 Mustahik.

Kedua, produktif dari segi ekonomi. Bantuan yang diberikan Zakat Center kepada Mustahik berupa prinsip hibah yaitu tambahan modal usaha dan modal tersebut tidak perlu ada pengembalian, bantuan tersebut diberikan kepada pedagang-pedagang kecil . Adapun prinsip qardhul hasan, merupakan bantuan pinjaman dana bergulir yang diberikan kepada mitra binaan yang mengajukan dana bergulir tersebut.

Namun secara umum, pendayagunaan dana zakat yang diwujudkan biasanya dalam bentuk pengembangan untuk usaha ekonomi, pembinaan sumber daya manusia, dan juga berupa bantuan konsumtif. Karena upaya-upaya tersebut dapat memutus suatu rantai kemiskinan, untuk itu LAZ Zakat Center memiliki beberapa program unggulan dalam pendayagunaan dana zakat produktif, yaitu:

1. Pembinaan terhadap Sumber Daya Manusia, melalui

a. Beasiswa yang diberikan kepada dhuafa yang akan melanjutkan ke jenjang SMP/MTs masa didikan selama 3 tahun, dan beasiswa ke perguruan tinggi

b. Pembinaan dan pendampingan mitra binaan dalam upaya perkembangan usahanya dan juga perkembangan spiritualnya 
2. Bantuan Usaha dari Zakat Produktif melalui Prinsip, melalui

a. Hibah (bantuan tanpa adanya pengembalian dana yang diberikan sebagai modal usaha tambahan.)

b. Qardhul Hasan (pinjaman kebaikan/dana bergulir, yaitu bantuan pinjaman tanpa adanya biaya tambahan/bunga).

Berdasarkan analisis di atas, dapat disimpulkan bahwa dampak penyaluran zakat produktif yang ada di Zakat Center dapat meningkatkan kesejahteraan Mustahik binaannya, karena dalam pemanfaatan dana zakat produktif pihak Zakat Center melaksanakan program penyaluran dana yang bertujuan untuk mensejahterkan Mustahik, pihak Mustahik pun merasakan adanya perubahan dari dana bantuan yang diberikan, baik dari segi ekonomi maupun spiritual yang cukup meningkat. Dana yang diberikan oleh Zakat Center dalam bentuk modal usaha dapat meningkatkan taraf hidup Mustahiknya. Hal tersebut dapat terlihat dari grafik dibawah ini:

Tingkat Kesejahteraan Mustahik Binaan

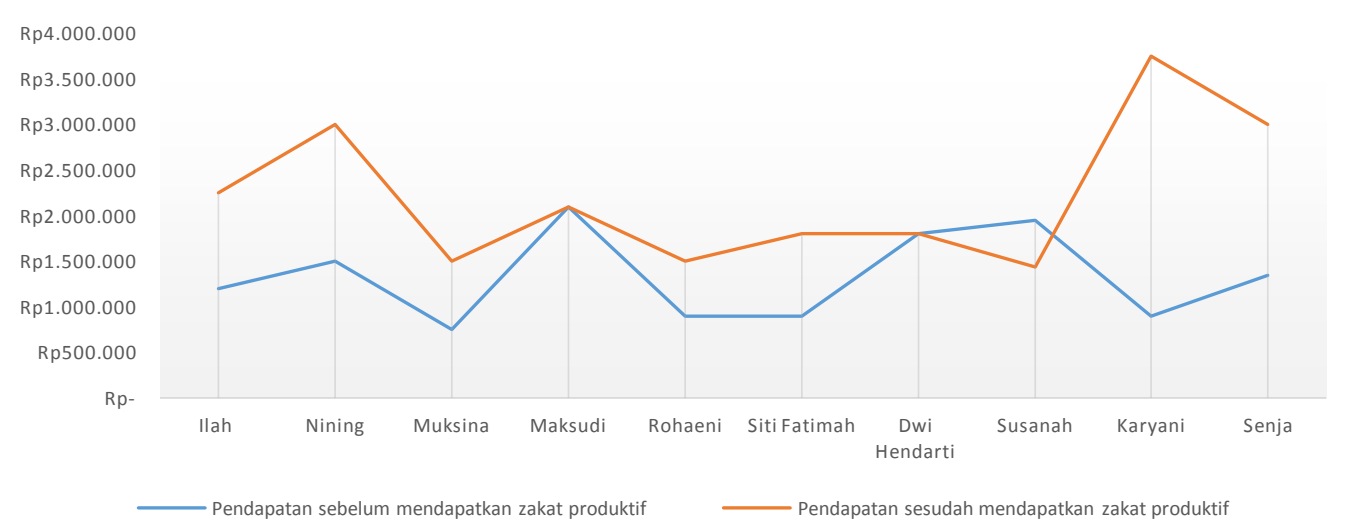

Grafik Tingkat Kesejahteraan Mustahik Binaan

\section{KESIMPULAN}

Proses pemberdayaan ekonomi Mustahik yang dilakukan oleh Zakat Center disusun secara terstruktur dan sistematis sangat berperan dalam meningkatkan penghasilan Mustahik. Kehadiran Zakat Center mampu mengurangi masalah sosial dan kemiskinan.

Peran pelaksanaan zakat produktif untuk Mustahik dapat meningkatkan perekonomian masing-masing keluarga Mustahik. Dengan adanya pemberdayaan pendistribusian zakat, perekonomian Mustahik mengalami perkembangan usaha, dan dapat meningkatkan.

Mekanisme penyaluran zakat produktif yang terdapat pada LAZ Zakat Center dalam bentuk pendanaan produktif-kreatif, yaitu penyaluran dana zakat yang diwujudkan dalam 
bentuk pemberian modal usaha yang berasal dari pengumpulan dana zakat maal diberikan pada Zakat Center untuk masyarakat yang kurang mampu, agar yang bersangkutan bisa lebih mandiri dan mampu mengembangkan usahanya melalui 5 (lima) golongan (asnaf) saja, yaitu; fakir, miskin, fisabilillah, ibnu sabil, dan muallaf. Pendistribusian zakat secara produktif dengan dua prinsip, yaitu hibah, dan qardhul hasan.

\section{DAFTAR PUSTAKA}

Aziz, Abdul. Manajemen Investasi Syariah. Bandung: Alfabeta, 2010.

BPS. "Kemiskinan," n.d. bps.go.id.

Et.All, Moh. Ali Aziz. Dakwah Pemberdayaan Masyarakat: Paradigma Aksi Metodologi.

Yogyakarta: Pustaka Pesantren, 2009.

Et.all, Nurul Huda. Ekonomi Pembangunan Islam. Jakarta: Prenadamedia Group, 2015.

Harahap, Emi Febrina. "Pemberdayaan Mayarakat Dalam Bidang Ekonomi Untuk Mewujudkan Ekonomi Nasional Yang Tangguh Dan Mandiri." Manajemen Dan Kewirausahaan 3, no. 2 (2014): 23.

Hilman. "Pemberdayaan Masyarakat Melalui Zakat Produktif." n.d.

Juliansyah, Noor. Metodologi Penelitian: Skripsi, Tesis, Disertasi, Dan Karya Ilmiah. Jakarta: Kencana Prenada Media Group, 2011.

Mardikanto, Totok dan Poerwoko Soebiato. Pemberdayaan Masyarakat. Bandung: Alfabeta, 2012.

Theresia, Aprillia et.all. Pembangunan Berbasis Masyarakat. Bandung: Alfabeta, 2014.

Tim Redaksi lqtishodia. "Mendudukan Arah Transformasi Lembaga Amil Zakat (LAZ)." Ekonomi Islam Republika 4, no. 2 (2010): 65.

Zakat Center. "Laporan Keuangan Zakat Center 2013-2017," n.d.

- - . "Laporan Penyaluran Dana 2017," n.d. 